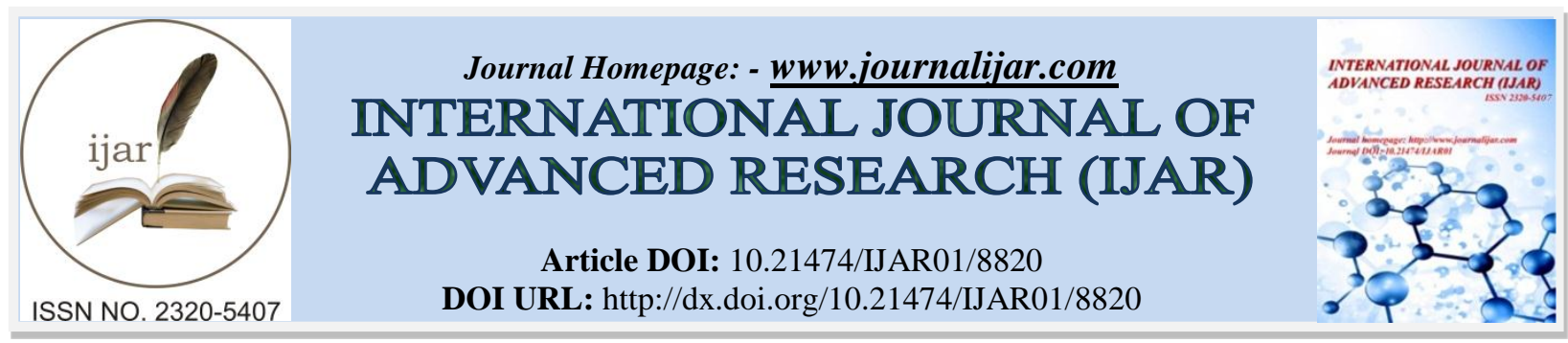

RESEARCH ARTICLE

\title{
CALISTHENICS ON STRESS AMONG ALCOHOL DEPENDENTS.
}

Subbiah Sathiyakani, Prabavathy S and Dr. Renuka K.

Department of Mental Health Nursing, Kasturba Gandhi Nursing College, Sri Balaji Vidyapeeth, Puducherry.

\section{Manuscript Info}

Manuscript History

Received: 05 February 2019

Final Accepted: 07 March 2019

Published: April 2019

Key words:-

Alcohol dependents, Stress, Calisthenics.

\begin{abstract}
Alcohol is a natural substance and exerts a depressant effects on the central nerve system, resulting in behavioral and mood changes and cause for death in both developed and developing countries. Alcohol dependence syndrome is a strong desire to take the substance and difficult in cutting of substance taking behavior and creating harm to self, traffic accidents, domestic violence and also psychological parameter changes like stress in alcohol dependents. Moreover, the number of studies found in South India over this topic are especially sparse. Hence, researcher has an interest in application of Calisthenics among alcohol dependents to reduce the stress and thereby promoting good psychological well-being and balancing the better outcome in health condition.
\end{abstract}

Copy Right, IJAR, 2019,. All rights reserved.

\section{Introduction:-}

Alcoholism is the major psychiatric, medical and public health problem and considered to be social and economic problems in developing countries like India. ${ }^{1}$ Alcoholism affects physical and mental health, and can cause problems with family, work place, serious impairment in social or occupational functioning. Alcohol misuse represents one of the prime cause of preventable death, illness and injury to individual, family and the society. ${ }^{2}$

Alcohol dependence syndrome is an entity in which alcohol is the only addict agent. It is a chronic disease with genetic, psychosocial and environmental factors have an influence on its development and detrimental to the individual. In India, many studies highlighted that health loss from alcohol is growing larger, to bring down this problem early identification and effective interventions are to be implemented for these habits. ${ }^{2}$ It can be succeed in achieving by learning to control the use of alcohol through social learning to help them to cope with their external pressures. ${ }^{3}$ Stress flatter too much that results in both psychological and biological changes. ${ }^{4}$

When danger is recognized, our body would deliver the chemical hormones like adrenaline, noradrenaline and cortisol into the blood stream and feeling the sense of danger. ${ }^{5}$ The stress hormones remain in our blood for a while and stave off us from relaxing, sleeping and enjoying life. ${ }^{5}$ Calisthenics play a part in directly to consider improvements in the quality of life. ${ }^{6}$

\section{Stress related alcohol dependence syndrome}

Stress refers to the reactions of the body to certain events or stimuli that the organism perceives as potentially harmful or distressful. Psychological stress like occupational and family difficulties are in nature that an individual become aware of more stressful event. Whenever a person understands the situation as stressful that leads to behavioral problems. The body neurochemical and hormone response are interrelated and play a part in to 
behavioral and emotional disturbance. Clinical experience and practice studies have estimated the influence of stress on drinking behavior and developing alcohol dependence syndrome. Most of the studies reviewed on prevalence among men and their socio-demographic variables. However, failed to address the possibility of heavy drinking and the life seriousness. Studies focused on occupational influences the drinking behavior and the prevalence rate of alcohol use among men $17.1 \%$. (Vijay Raman et al- 2017). ${ }^{7}$ The co-morbidity prevalence rate of stress $38 \%$ (Suvitha-2017). ${ }^{8}$

Stressful events that provide inducement to an alcoholic person to seek treatment, when other sources and responses have failed to mitigate their stressful situation. Studies initiated group therapy for psychological well-being among alcohol dependents $37.5 \%$ (Sugumar-2016). ${ }^{9}$ Stress plays a casual role in the initiation of treatment and the Calisthenics exercises is the better choice to reduce the stress among alcohol dependents. ${ }^{10}$

\section{Stress and Calisthenics.}

Calisthenic exercises increase us to fell overall welfare and has got direct stress- snapping benefits. Calisthenics helps to raise the level of producing the happy endorphins and begins to shed our daily routine with take it easy movements and increasing stamina and buoyancy and also helps to endure calm and clear in doing day to day activities. Calisthenics can increase self-esteem, relaxation, and improve good sleep which is disrupted by stress. ${ }^{11}$ The 20 minutes of walking exercises have more benefits on our body merely the absence of disease or infirmity. ${ }^{12}$ Walking can make our brain in to calm, and shift to meditative state. Group walking can added benefits of spending time with friends and initiate social bonding. Walking with friends and pet animals will increase the stress resilience and reduce the level of cortisol which is inducing stress. ${ }^{13}$ Squat Calisthenics can be performed which helps in muscle strengthening and fitness. En.m.wikipedia.org. Sun-salutation squat can be performed for 5 counts to improve the level of relaxation. ${ }^{14}$ Calisthenic exercises ameliorate our body's ability to use oxygen and improves blood flow. Calisthenic exercises promote our body to produce feel-good endorphins and helps our mind free from worries. Regular calisthenics promotes optimum health and moderate the stress levels. Other benefits of Calisthenic exercises can strengthen the muscles, bones, strengthen immunity level, increased blood circulation, improve sleep, and self-image. ${ }^{15}$

The study findings are presented as follows:

Table: 1: Fig: 1: depict the pre-test experimental group $45.5 \%$ had severe Stress and 54.5\% had extremely Stress and none of them belong to mild and moderate Stress. In control group $48.5 \%$ had severe Stress and $51.5 \%$ had extremely Stress.

Table: 1:, Fig:2: highlighted the post-test experimental group $69.7 \%$ had belong to normal level and $27.3 \%$ had mild Stress and none of them belong to moderate, severe and extremely severe Stress. In control group $9.1 \%$ had moderate Stress $84.8 \%$ had severe Stress and 6.1\% had extremely severe Stress.

Table-1: Assessment of pretest and posttest level of Stress among experimental and control group of Alcoholic dependents

\begin{tabular}{|l|l|l|l|l|}
\hline \multirow{2}{*}{ Level of Stress } & Experimental group & \multicolumn{2}{l|}{ Control group } \\
\cline { 2 - 5 } & Pre-Test & Post-Test & Pre-Test & Post-Test \\
\hline Normal & 0 & 69.7 & 0 & 0 \\
\hline Mild & 0 & 27.3 & 0 & 0 \\
\hline Moderate & 0 & 3 & 0 & 9.1 \\
\hline Severe & 45.5 & 0 & 48.5 & 84.8 \\
\hline Extremely Severe & 54.5 & 0 & 51.5 & 6.1 \\
\hline
\end{tabular}




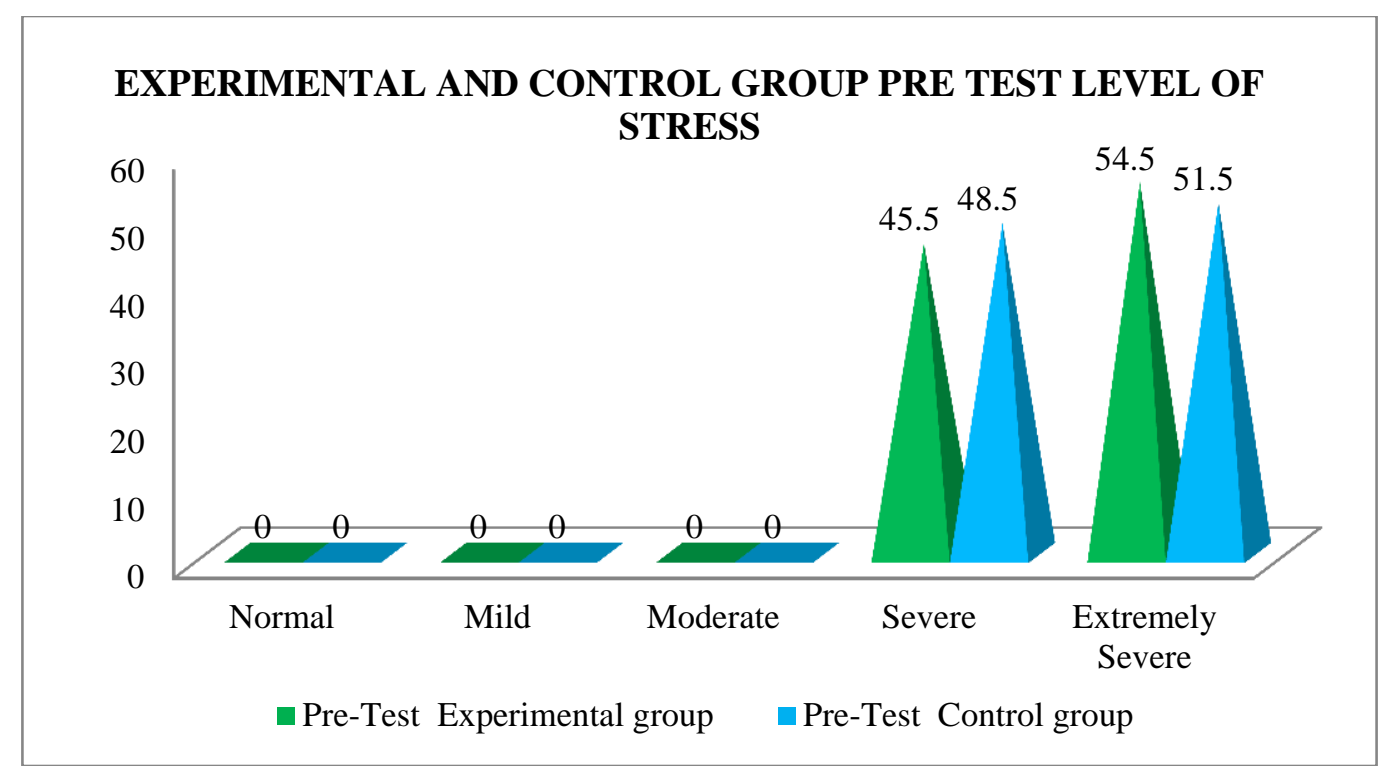

Figure- 1 Assessment of Pre - test level of Stress among experimental and control group of alcoholic dependents

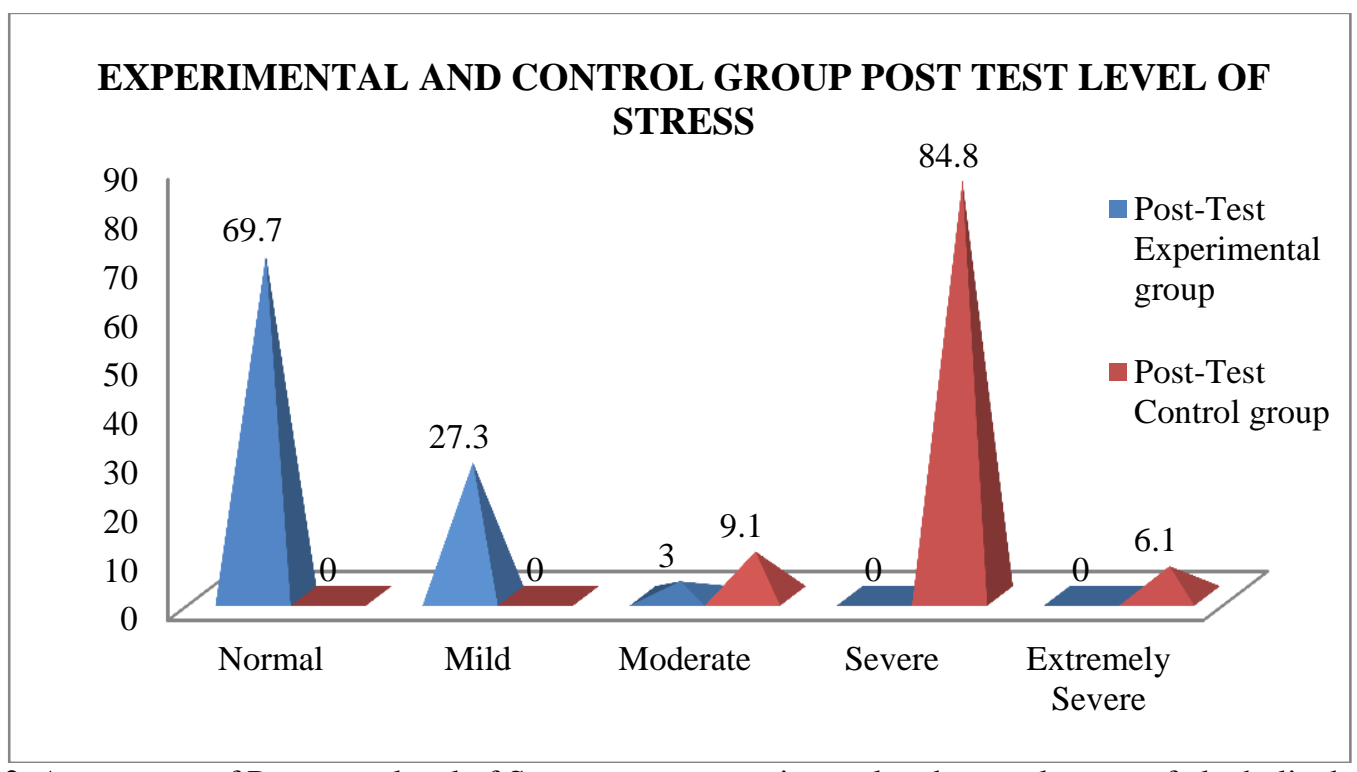

Figure-2. Assessment of Post - test level of Stress among experimental and control group of alcoholic dependent

\section{Conclusion:-}

As a researcher, administered Calisthenic exercises which include Walking, Side- bending, Squats, Lunges and Frog crunches with 1 minute rest, repeat 2 times for each exercises, total 30 minutes every day for 21 days and statically proved the improvement in reducing the stress level. The study finding reveals that after 21 days of calisthenics intervention there is an effective change in the experimental group then the control group to reduce the Stress level among alcohol dependents. Calisthenics exercises need not have special equipment, special place and cost effective. It can administered for all the age group people. The researcher administered to alcohol dependents to reduce their stress level.

\section{Relevance to clinical practice}

Self-initiated reconfiguration of person environment interactive patterns is essential to overcome stress. Calisthenics could be given to alcohol dependents on a regular basis in the clinical settings and in rehabilitative centre in order to improve their mental well-being, their caregivers could also practice it whenever possible. 


\section{Reference:-}

1. iosrjournals.org. - Google Search

2. https://ijcmph.com/index.php/ijcmph

3. Wikipedia, the free encyclopedia

4. J. Goldberger and S.Breznitz (Eds), 2004, Handbook of stress-theoretical and clinical aspects LP-185.

5. Baskararaj E, mental Health Nursing, 1st edition, EMMESS publication (2014), page no 213-215. - Google Search

6. Van Gils Y, Van Rompacy B, Dierckx E. The association between drinking behavior wellbeing and late life alcohol use problems: proc. Social behavior 293. Page no 592-8.

7. V. Vijay Ramanan et al, A study on alcohol use its related health and social problems in rural Puducherry, India. March 17 IP 217; 33, 247,218.

8. Suvitha Psychiatric Comorbidity among alcohol dependents. International journal of current trends in science and technology, 2017. http:// doi.org/10.15520/ctst.v till.105. Page no MS 20369-20373.

9. www.iosrjournals.org

10. https//pubs.niaaa.nih.gov

11. .mayoclinic.org

12. Verywellfit.com

13. Huffpost.com

14. Chatelaine.com

15. Healthline.com 